\title{
Supratentorial arachnoidal cyst associated with hydrocephalus
}

\author{
J. GRUSZKIEWICZ AND E. PEYSER \\ From the Department of Neurosurgery, Rambam Government Hospital, Haifa, Israel
}

Supratentorial arachnoidal cysts are usually associated with signs of fracture of the skull but hydrocephalus has not been reported in connexion with such cysts. In none of the 18 cases reviewed by Tiberin and Gruszkiewicz (1961) was hydrocephalus found. A 3-year-old child was recently seen with signs of hydrocephalus and a large arachnoidal cyst of the right cerebral hemisphere. The rarity of such an association warrants this report.

\section{CASE HISTORY}

A 3-year-old girl was admitted to the Department of Neurosurgery on 14 August 1962 with a presumptive diagnosis of progressive hydrocephalus. Delivery had been at term and without complications. When she was 6 weeks old she fell out of bed, injured her head, and was rendered unconscious for a few minutes. She was admitted to another hospital, but no clinical details are available. It was noticed that subsequently her head grew larger out of all proportion until the age of 9 months, when this abnormal growth ceased.

On admission, the child appeared underdeveloped both physically and mentally. She was unable to walk, sit, or hold her head up without support. There was a marked spastic right hemiparesis. The shape of the head appeared hydrocephalic. The skull was asymmetrical, the right half bulging and wider than the left. Exophthalmos was noticed on the right and a positive 'sunset phenomenon' in both eyes. The circumference of the head was $63 \mathrm{~cm}$. The anterior fontanelle was still widely open, tight and bulging. Both optic nerve disks were pale. Visual acuity and visual fields on confrontation appeared normal. The range of eye movements was full. The tendon reflexes were slightly exaggerated on the right.

Radiographs of the skull showed tremendous enlargement of the head with bulging of its right half. The electroencephalogram showed low-voltage slow waves in the right parieto-occipital region and a minor disturbance in the left temporal region. It was thought that this record was compatible with a collection of fluid over the right parietal region of the brain.

A lumbar puncture was performed and clear cerebrospinal fluid under a pressure of $180 \mathrm{~mm}$. water was obtained. It contained $30 \mathrm{mg} / 100 \mathrm{ml}$. protein, 120 mEq./l. chlorides, and 10 lymphocytes and 17 polymorphonuclear cells per c.mm. The mastix test and Wassermann reaction were negative. An attempt at pneumoencephalography was unsuccessful; ventriculo-

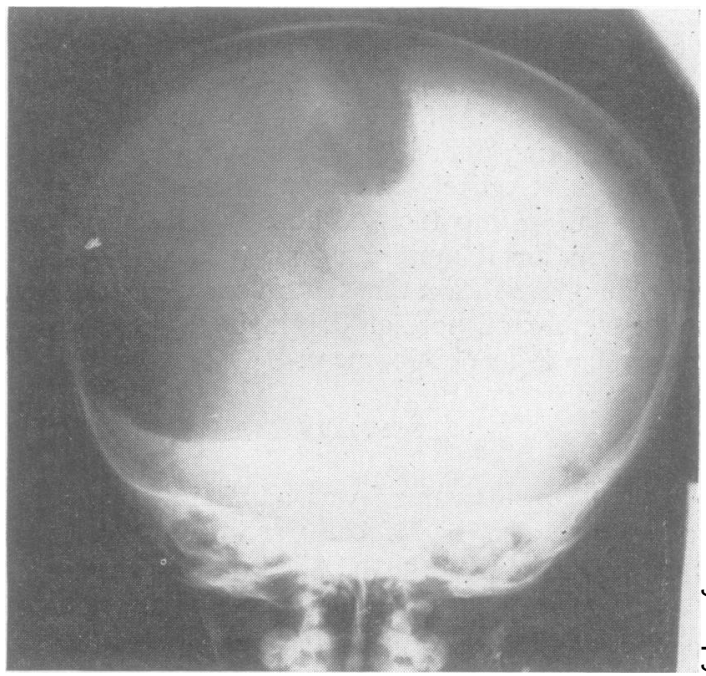

FIG. 1 .

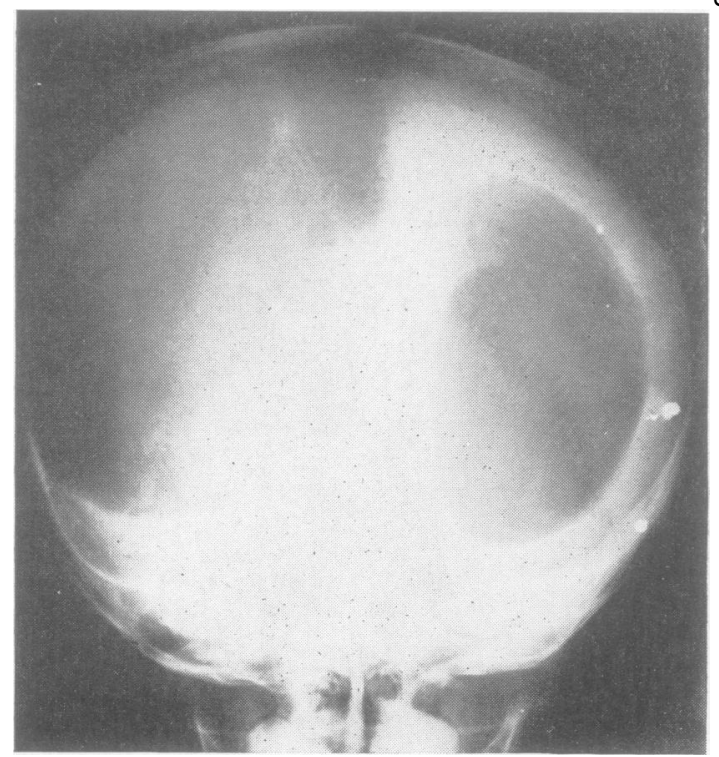

FIGS. 1 and 2. Antero-posterior view showing enormous cyst covering the right hemisphere (above), and below air-filled cyst and enlarged left ventricle. 


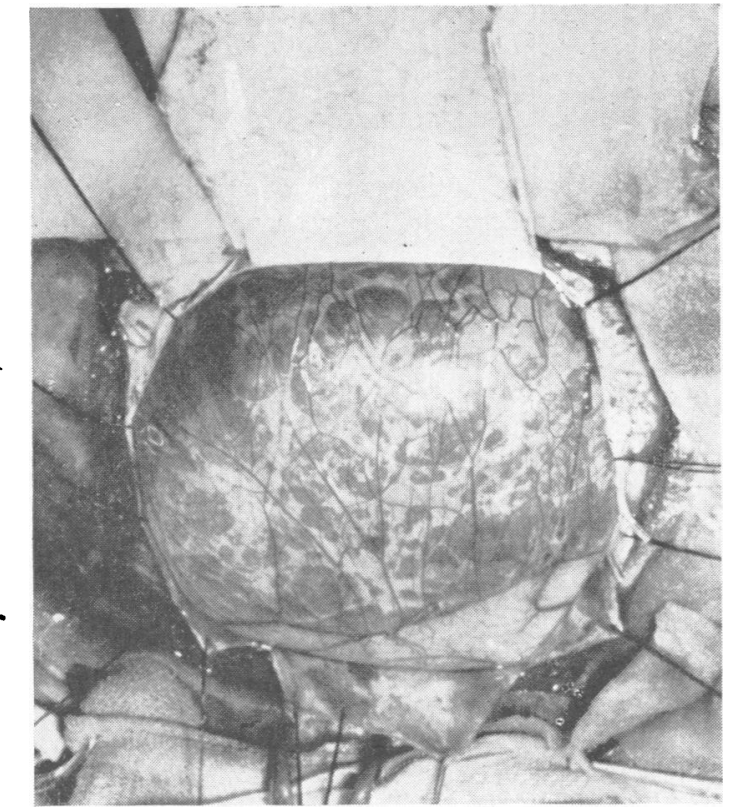

FIG. 3 .

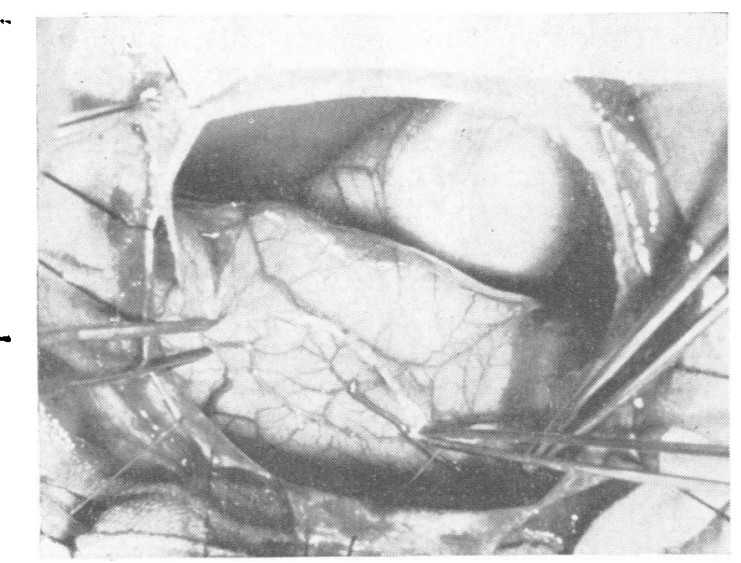

FIG. 4.

FIGS. 3 and 4. Operative field after opening of the dura (above), showing the lateral cyst wall and displaced right hemisphere, and (below) after excision of cyst wall and evacuation of fluid. The displaced hemisphere is raised.

graphy was, therefore, deemed advisable. Xanthochromic fluid was obtained by a puncture through the right side of the anterior fontanelle, containing $200 \mathrm{mg}$. of protein per $100 \mathrm{ml}$; $160 \mathrm{ml}$. of fluid was exchanged with air. Radiographs showed air only on the right side (Fig. 1). Therefore, puncture through the left side of the anterior fontanelle was accomplished. Clear fluid was obtained with a protein content of $30 \mathrm{mg}$. per $100 \mathrm{ml}$.; $80 \mathrm{ml}$. was exchanged with air. Radiographs showed tremendous enlargement of the left lateral ventricle. On the right side,

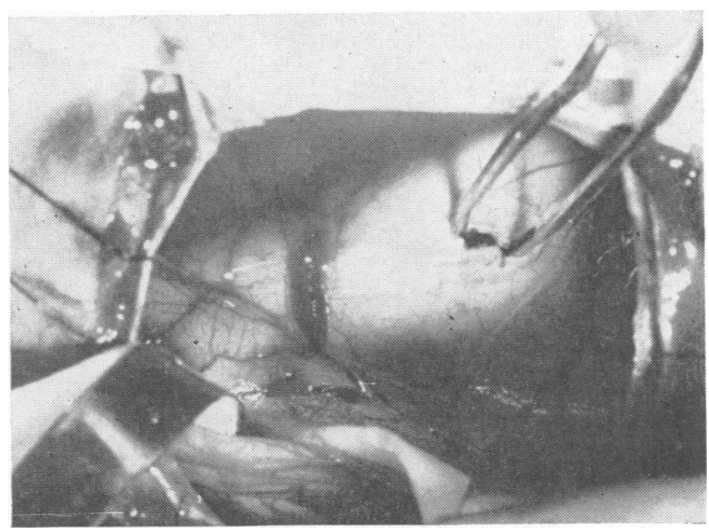

FIG. 5. Opening of third ventricle through distended corpus callosum.

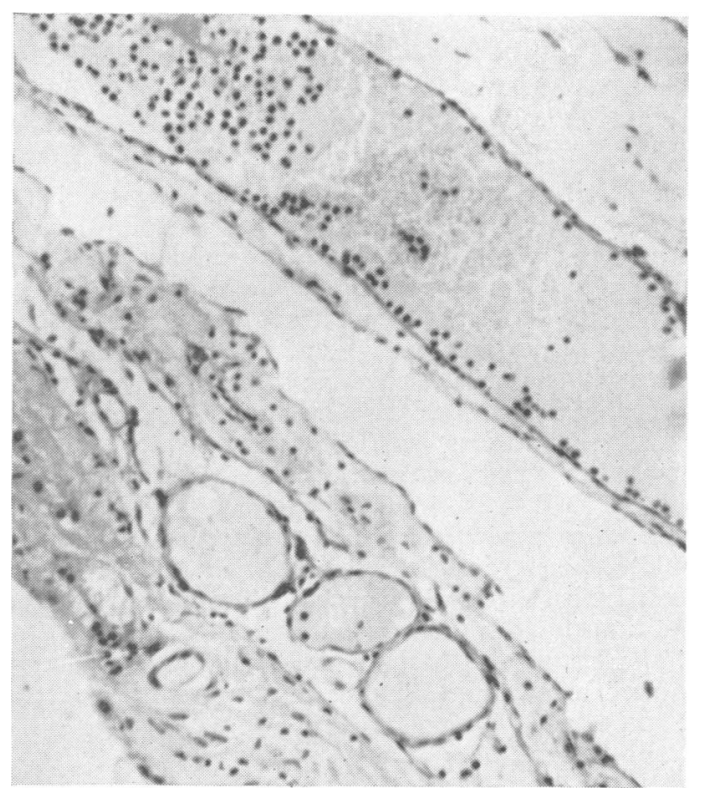

FIG. 6. Two parts of the cyst wall consisting of loose connective tissue with many thin-walled blood vessels (arachnoides). Haematoxylin and eosin $\times 320$.

however, the air extended toward the internal table of the skull laterally, and up to the midsagittal plane medially (Fig. 2).

Considering the result of the air studies and the different protein contents in the fluids obtained, it was suspected that a cystic cavity was present on the right side of the brain.

OPERATION On 29 August under general anaesthesia, a right fronto-parieto-temporal bone flap was elevated. The dura was transparent and very tense, and fluid and 


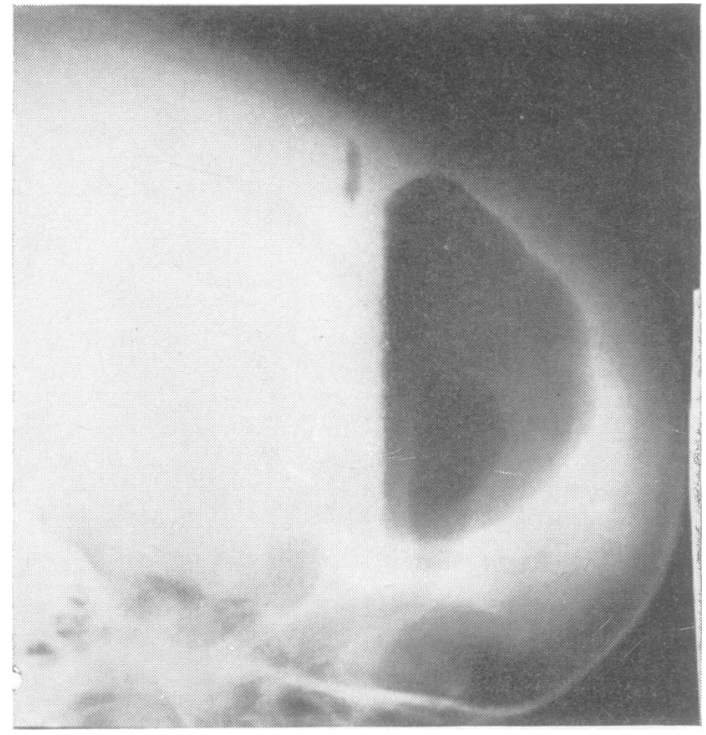

FIG. 7. Brow-up pneumoencephalogram at follow-up, showing filling of both lateral ventricles.

bubbles of air could be seen through it. After opening the dura, it was noted that the major part of the right hemisphere was covered by an enormous cyst with the arachnoid forming its walls. The temporal lobe was atrophic, with small and flattened gyri. In the walls of the cyst there were several blood vessels continuous with those of the pia mater covering the brain (Figs. 3 and 4).

The cyst wall was excised and part of it removed for examination. Clear xanthochromic fluid escaped, and about $750 \mathrm{ml}$. was evacuated from within the cyst. After the cyst had been emptied a white structure was seen, which was punctured with a brain cannula and clear fluid obtained, probably from the right lateral ventricle. Ventriculostomy was therefore performed (Fig. 5), and the dura closed in the usual way.

The histological examination of the wall of the cyst showed a membrane similar in structure to arachnoid (Fig. 6).

POST-OPERATIVE COURSE This was uneventful except for some elevation. of temperature during the first fortnight. Repeated lumbar punctures following the operation showed that pressure and composition of the cerebrospinal fluid had returned to normal by the end of three weeks.

The patient was discharged from hospital 25 days after the operation, much improved. She was able to hold up her head and sit without support. The weakness of the right extremities had almost disappeared, and the fontanelle was no longer bulging. The child was readmitted for follow-up investigation two and a half months later. Control pneumoencephalography showed free communication within the ventricular system with filling of both lateral ventricles. No air was seen in the cranial subarachnoid spaces, obviously showing that the opening made in the roof of the third ventricle at operation had sealed off (Fig. 7).

\section{DISCUSSION}

The aetiology and pathogenesis of arachnoid cysts are not well understood. They have been divided into four groups according to their origin.

1 Developmental malformation and localized brain atrophy, a condition for which Robinson (1958) suggested the term 'external hydrocephalus' which, in his opinion, was due to localized agenesis of the brain.

2 Inflammatory, as described by Horrax (1924), de Martel and Guillaume (1930), and others, in which otitis media, nasal sinus infections, meningitis have been found.

3 Traumatic, with fracture of the skull as reported by Taveras and Ransohoff (1953), Peyser and Weissberg (1961), and others, in which cases localized post-traumatic brain damage was found with laceration of the dura and the formation of porencephalic and leptomeningeal cysts.

4 Traumatic, usually after minor injury, but without fracture of the skull: Cohen (1927), Childes (1953), Tiberin and Gruszkiewicz (1961), and others have reported such cysts, usually located in theD middle cranial cavity.

After even minor trauma without skull fracture localized subarachnoid bleeding may occur with haematoma forming. Adhesions develop because of difference in osmotic pressure, the haematoma in creases in size, and a collection of fluid rich in protein is formed.

Supratentorial arachnoid cysts are usually located in the middle cranial cavity (Sylvian or Rolandic fissure) or between the hemispheres. Clinically they may remain silent and will only be detected on postmortem examination. If, however, they cause focal neurological signs, these are usually of a minor degree. Air studies and arteriography may be helpful in making the diagnosis, but ultimately only surgical exploration will establish the nature of the lesion.

Arachnoid cysts which are the result of a developmental anomaly were shown by gross and microscopic examination to lie between two arachnoid membranes. They are, therefore, in fact intraarachnoid cysts (Starkman, Brown, and Linell, 1958). Other 'cysts', which are the result of brain atrophy, are not true cysts but localized enlargement of the subarachnoid space. It may be extremely difficult to differentiate between the two conditions.

Differential diagnosis will have to take into consideration subdural hygromas and subdural haematomas, which are characterized by the formation of neo-membranes around the fluid collection. Histo- 
logical examination of the cyst wall will help in arriving at a correct diagnosis.

The present case seems to be one of congenital hydrocephalus associated with a huge arachnoid cyst. Though a developmental anomaly cannot entirely be excluded, the traumatic origin of the cyst should seriously be considered.

\section{SUMMARY}

The case of a 3-year-old girl with hydrocephalus and an arachnoid cyst is presented. It resulted in pressure on the right cerebral hemisphere and local bulging of the skull. Surgical treatment resulted in remarkable clinical improvement.

The origin of such cysts is discussed.

Our thanks are due to Mrs. B. Kulka for the photographs.
REFERENCES

Childe, A. E. (1953). Localized thinning and enlargement of the cranium, with special reference to the middle fossa. Amer. J. Roentgenol., 70, 1-21.

Cohen, I. (1927). Chronic subdural accumulations of cerebrospinal fluid after cranial trauma. Arch. Neurol. Psychiat. (Chic.), 18, 709-723.

Horrax, G. (1924). Generalized cisternal arachnoiditis simulating cerebellar tumor: its surgical treatment and end-results. Arch. Surg. (Chic.), 9, 95-112.

de Martel, T., and Guillaume, J. (1930). Sept cas de néoformations de la fosse occipitale opérés et guéris. Rev. Neurol., 2, 537-545.

Peyser, E., and Weissberg, D. (1961). Post-traumatic arachnoidal cyst. J. Neurosurg., 18, 551-553.

Robinson, R. G. (1958). Local bulging of the skull and external hydrocephalus due to cerebral agenesis. Brit.J. Radiol., 31, 691-700.

Starkman, S. P., Brown, T. C., and Linell, E. A. (1958). Cerebral arachnoid cysts. J. Neuropath. exp. Neurol., 17, 484-500.

Taveras, J. M., and Ransohoff, J. (1953). Leptomeningeal cysts of the brain following trauma with erosion of the skull. J. Neurosurg., 10, 233-241.

Tiberin, P., and Gruszkiewicz, J. (1961). Chronic arachnoidal cysts of the middle cranial fossa and their relation to trauma. J. Neurol. Neurosurg. Psychiat., 24, 86-91.

\section{The August 1965 Issue THE AUGUST 1965 ISSUE CONTAINS THE FOLLOWING PAPERS}

Involuntary movements following stereotactic operations for Parkinsonism with special reference to hemi-chorea (ballismus) BRODIE HUGHES

Stereotactic tractotomy in the surgical treatment of mental illness GEOFFREY KNIGHT

Facial nerve preservation by posterior fossa transmeatal microdissection in total removal of acoustic tumours R. W. RAND and T. L. KURZE

Cerebral tumour presenting with hyperventilation L. S. LANGE and G. LASZLO

On the nature of the peripheral nerve lesions associated with acute intermittent porphyria J. B. CAVANAGH and R. S. MELLICK

Spread of phasic muscle reflexes in normal and spastic subjects J. W. LANCE and P. DE GAIL
Simultaneous bilateral cerebral blood flow and metabolism with arteriographic correlation in unilateral brain infarction or haemorrhage E. BETETA, P. SCHEINBERG, o. M. REINMUTH, S. SHAFEY, and S. SHIMOJYO

A peculiar type of post-concussive 'blackout' LEONARD D. OSLER and MICHAEL G. FUSILLO

An ataxic form of subacute presenile polioencephalopathy (Creutzfeldt-Jakob disease) BETTY BROWNELL and D. R. OPPENHEIMER

Observations on the pathology of the Moebius syndrome SAMUEL E. PITNER, JAMES E. EDWARDS, and WILLIAM F. MCCORMICK

Ocular bobbing ROBERT B. DAROFF and ARTHUR $L$. WALDMAN

Disorders of magnesium metabolism in epilepsy HORACIO M. CANELAS, Luís MARQUES DE ASSIS, and FRANCISCO B. DE JORGE

Book reviews

Copies are still available and may be obtained from the PUBLISHING MANAGER, BRITISH MEDICAL ASSOCIATION, TAVISTOCK SQUARE, W.C.I price, 18s. 6D. 